\title{
Power generation from low grade waste heat using thermoelectric generator
}

\author{
Sohel Rana ${ }^{1}$, Arbab Iqbal ${ }^{1}$, Abhijit Date $^{1}$, Aliakbar Akbarzadeh ${ }^{1}$ \\ ${ }^{1}$ Energy Conservation and Renewable Energy, School of Mechanical and Automotive Engineering, RMIT University, Bundoora East \\ Campus-3083, Australia
}

\begin{abstract}
Thermoelectric technology is thought to be a great solution in near future for producing electrical power and recovering low grade waste heat to cut the cost of power generation because of its consistency and eco-friendly affability. Though commercial accessibility of TEG is available currently but heat to electricity conversion efficiency is still low and cost of the module is reasonably high. It's essential to use the modules competently which is strongly depends on suitable heat exchanger design and selection of proper operating conditions. In this work, TEG module has been selected from the commercially available modules with efficiency of $1.91 \%$ for the targeted low-grade waste heat temperature of $\mathrm{T}_{h}=90^{\circ} \mathrm{C}$ and $\mathrm{T}_{\mathrm{c}}=15^{\circ} \mathrm{C}$ which validated by experiment. Mathematical model has been proposed to simulate TEG based power generation system; the model can predict maximum net power, choose optimum operating conditions and dimensions of heat exchanger. Lab scale design with channel length $1 \mathrm{~m}$, width $0.08 \mathrm{~m}$ and gap size $9 \mathrm{~mm}$ which is suitable for 50 TEG module $(4 \mathrm{~mm} \times 4 \mathrm{~mm}$ ) have been simulated using proposed mathematical model. For above temperature range, predicted optimum net power was $76.45 \mathrm{~W}$ with optimum flow rate $0.94 \mathrm{~L} / \mathrm{s}(56.4 \mathrm{~L} / \mathrm{min})$. This lab scale setup will be used for experimental validation of the proposed mathematical model. The obtained results from experiments and simulation are closely matched.
\end{abstract}

\section{Introduction}

In recent years, there are clear attempts to recoup the waste heat and produced electrical power using different source of waste energy such as cars, power plant, telecommunication, industries, automobiles, cooling systems, solar, geothermal, solar ponds and so on. These attempts have been led towards lessening the generation cost of electricity and diminishing the air contamination worldwide. Though, petroleum is still principle hotspot for producing electrical power. I major parts of this consumed energy is wasted as heat $[1,2]$.

Based on temperature, waste heat can be classified into low grade (below $230^{\circ} \mathrm{C}$ ), medium (between $230^{\circ} \mathrm{C}$ to $630^{\circ} \mathrm{C}$ ) and high temperature (above $630^{\circ} \mathrm{C}$ ) and a typical example of waste heat and its work potential has shown in figure 1 [3-6].

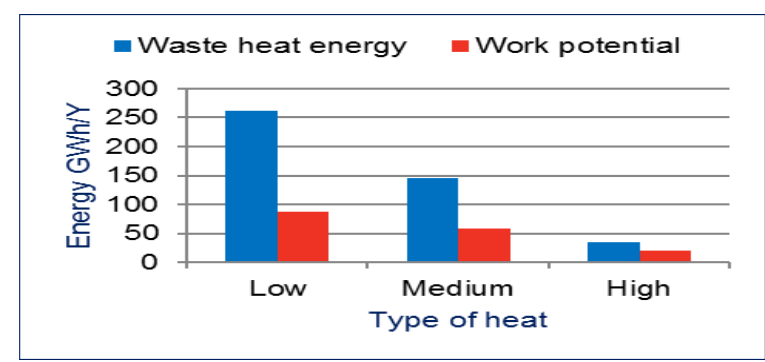

Fig. 1. Waste heat and its work potential
There are several technologies can be found to generate electricity from low grade waste heat such as organic Rankine cycle, thermoelectric, water desalination and piezoelectric. Thermoelectric technology is supposed to be an alternative way to recover low grade waste heat; which can convert heat to electrical power and vice versa. Though thermoelectric has low conversion efficiency and costly; it has no moving parts and does not require maintenance which attracting to use this technology.

Low grade waste heat recovery using thermoelectric has been studied theoretically as well as experimentally from last few decades. From literature, some important related findings have been studied and summary has been listed in Table 1.

Table 1: Summary from related literature

\begin{tabular}{|c|c|c|c|c|}
\hline $\begin{array}{c}\text { Author(s) } \\
\text { \& year }\end{array}$ & $\begin{array}{c}\text { Type } \\
\text { of } \\
\text { work }\end{array}$ & $\begin{array}{c}\text { Hot side \& cold } \\
\text { side temperature }\end{array}$ & $\begin{array}{c}\text { TEG } \\
\text { module } \\
\text { number }\end{array}$ & $\begin{array}{c}\text { Achieveme } \\
\text { nts }\end{array}$ \\
\hline $\begin{array}{c}\text { Rowe et } \\
\text { al } \\
(1997)[7]\end{array}$ & Exp & $\begin{array}{c}\text { Hot water }=90^{\circ} \mathrm{C}, \\
\text { Cold water }=14^{\circ} \mathrm{C}\end{array}$ & 36 & $\begin{array}{c}\text { Max. power } \\
=95 \mathrm{~W}\end{array}$ \\
\hline $\begin{array}{c}\text { Crane et } \\
\text { al } \\
(2004)[8]\end{array}$ & Exp & $\begin{array}{c}\text { Hot water }=90^{\circ} \mathrm{C}, \\
\text { Cold air }=25^{\circ} \mathrm{C}\end{array}$ & 6 & $\begin{array}{c}\text { Max. } \\
\text { power }=0.54 \\
\mathrm{~W}\end{array}$ \\
\hline $\begin{array}{c}\text { Niu et al } \\
(2009)[9]\end{array}$ & Exp & $\begin{array}{c}\text { Hot fluid }=90^{\circ} \mathrm{C}, \\
\text { Cold fluid }=25^{\circ} \mathrm{C}\end{array}$ & 56 & $\begin{array}{c}\text { Max power } \\
=146.5 \mathrm{~W}\end{array}$ \\
\hline $\begin{array}{c}\text { Gou et al } \\
(2010)[10]\end{array}$ & Exp & $\begin{array}{c}\text { Hot water }=80^{\circ} \mathrm{C}, \\
\text { Cold air }=24^{\circ} \mathrm{C}\end{array}$ & 10 & $\begin{array}{c}\text { Max. power } \\
=0.85 \mathrm{~W}\end{array}$ \\
\hline
\end{tabular}




\begin{tabular}{|c|c|c|c|c|}
\hline $\begin{array}{l}\text { Kim et al } \\
(2011)[11]\end{array}$ & Exp & $\begin{array}{l}\text { Hot water }=95^{\circ} \mathrm{C}, \\
\text { Cold air }=45^{\circ} \mathrm{C}\end{array}$ & 72 & $\begin{array}{c}\text { Max. power } \\
= \\
75 \mathrm{~W}\end{array}$ \\
\hline $\begin{array}{c}\text { Gou et al } \\
(2013)[12]\end{array}$ & Exp & $\begin{array}{l}\text { Hot water }=90^{\circ} \mathrm{C}, \\
\text { Cold air }=28.5^{\circ} \mathrm{C}\end{array}$ & 18 & $\begin{array}{c}\text { Max. power } \\
=6.5 \mathrm{~W}\end{array}$ \\
\hline $\begin{array}{l}\text { B. Orr et al } \\
(2016)[13]\end{array}$ & Exp & $\begin{array}{l}\text { Hot exhaust air } \\
=218^{\circ} \mathrm{C}, \text { Cold } \\
\text { air }=31^{\circ} \mathrm{C}\end{array}$ & 8 & $\begin{array}{l}\text { Max. power } \\
=38 \mathrm{~W}\end{array}$ \\
\hline $\begin{array}{l}\text { Remeli et } \\
\text { al } \\
(2016)[4]\end{array}$ & Exp & $\begin{array}{l}\text { Hot air }=160^{\circ} \mathrm{C}, \\
\text { Cold air }=65^{\circ} \mathrm{C}\end{array}$ & 1 & $\begin{array}{l}\text { Max. power } \\
=1.72 \mathrm{~W}\end{array}$ \\
\hline
\end{tabular}

All these studies were experimental and some of them were able to generate significant amount of electrical power. So, above literature only concentrated on testing commercially available TEG performances; none of current literature make known to an optimization technique to maximize the net electrical power by considering losses due to thermal resistance and parasitic power losses. In this works, a system has considered which consisted thermoelectric modules sandwiched between hot water and cold-water channel. TEG can produced electricity from the temperature difference between hot and cold water. This power generation is increased with the higher temperature difference and higher mass flow rate, but there is a penalty for higher mass flow rate called parasitic loss. This parasitic loss also depends on the size of the heat exchanger. So, the amount of net power/ useful power from this system depends on size of channel, mass flow rate, efficiency of TEG modules, number of modules and parasitic power. For chosen TEG modules, efficiency is fixed and number of TEG has considered also fixed for this study. So, maximum net power depends on proper selection of length, width and gap height of water channel and depends on suitable selection of mass flow rate. The novelty of this study is proposed mathematical model to predict gross power, parasitic power and net power where mass flow rate, gap height, length and width have taken as variables. Number of TEG and its property (such as dimensions, efficiency and thermal resistance) have considered as fixed. As the number of TEG and its dimensions fixed, channel length and width are interrelated [6]. Proposed model will help to predict maximum net power, optimized channel dimensions and suitable flow rate for defined conditions. Predicted results from proposed model will be validated by experiments. This model will be useful for system optimisation.

\section{Selection of thermoelectric generator}

Based on market research, we have carefully selected five different high performance thermoelectric modules presented in figure 2. These five thermoelectric modules are Seebeck based (generator) have been chosen based on the performance data sheet given by manufacturer and price. A number of experiments have been done using TEG testing setup shown in figure 3. Experiment has been run for similar operating conditions with hot side temperature $\mathrm{T}_{\mathrm{h}}=90^{\circ} \mathrm{C}$ and cold side temperature $\mathrm{T}_{\mathrm{c}}=15^{\circ} \mathrm{C}$ and recorded generated power from selected modules. Since module size and price are not identical, we have been selected two properties $\left(\mathrm{kW} / \mathrm{m}^{2}, \$ /\right.$ Watt $)$ for an uniform comparison. Power generation per square meter $\left(\mathrm{kW} / \mathrm{m}^{2}\right)$ will give an idea about the power generation capability TEG module and $\$ / \mathrm{W}$ is required to get an idea about power production cost of per unit electricity. These two properties can be calculated from experimentally measured data and module price. Dimensions of five modules, maximum operating temperature, calculated properties for targeted temperature has been shown in Table 2.

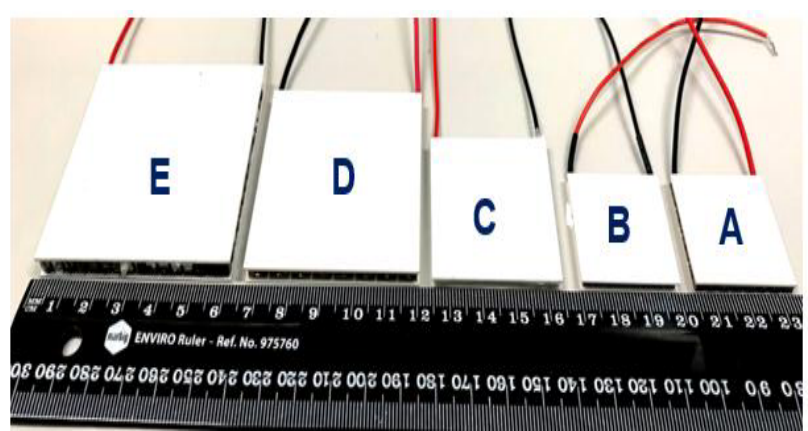

Fig. 2. Selected thermoelectric module

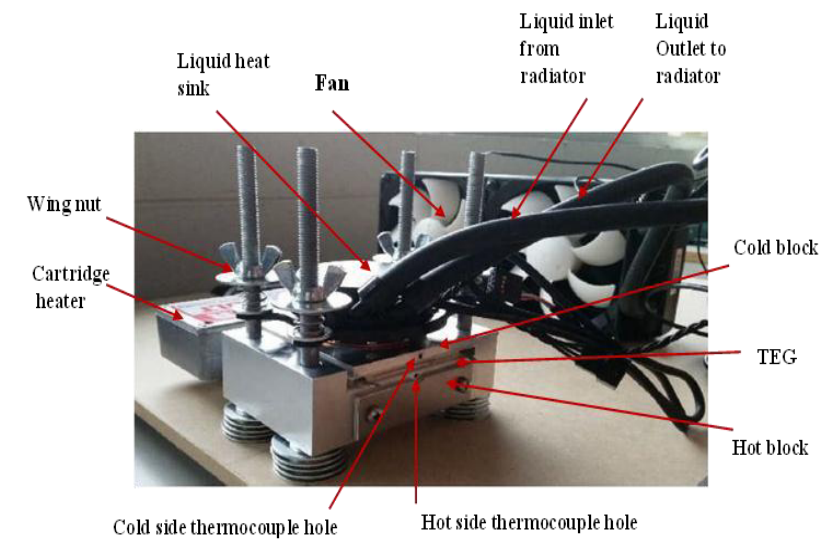

Fig. 3: TEG testing setup

Table 2: Experimental performance of selected TEG

\begin{tabular}{|c|c|c|c|c|c|c|c|}
\hline Module & $\begin{array}{c}\mathrm{L} \times \mathrm{W} \\
(\mathrm{mm})\end{array}$ & $\begin{array}{c}\mathrm{h} \\
(\mathrm{mm} \\
)\end{array}$ & $\begin{array}{l}\mathrm{T}_{\mathrm{h}} \mathrm{o}^{\circ} \\
\mathrm{C})\end{array}$ & $\begin{array}{l}\mathrm{T}_{\mathrm{c}}{ }^{\mathrm{o}} \\
\mathrm{C})\end{array}$ & $\begin{array}{c}\mathrm{kW} / \\
\mathrm{m}^{2}\end{array}$ & $\$ / W$ & $\begin{array}{c}\operatorname{Max} \\
(\Delta \mathrm{T})\left(^{\circ}\right. \\
C) \\
\end{array}$ \\
\hline A & 30 & 3.7 & 90 & 15 & 0.73 & 37 & 140 \\
\hline B & 30 & 3.8 & 90 & 15 & 0.66 & 29 & 140 \\
\hline $\mathrm{C}$ & 40 & 3.2 & 90 & 15 & 1.08 & 12 & 90 \\
\hline D & 55 & 3.8 & 90 & 15 & 0.63 & 40 & 170 \\
\hline E & 62 & 6.3 & 90 & 15 & 0.16 & 18 & 270 \\
\hline
\end{tabular}

Another important parameter is efficiency of TEG under the specified operating condition; where TEG efficiency can be defined as the conversion ability of heat to electrical power. Another experiment has been undertaken using TEG testing rig to measure efficiency of selected thermoelectric module. The obtained efficiency for five modules has plotted in figure 3. By analysing table 2 and figure 4 , we can conclude that 
module $\mathrm{C}$ is utmost suitable for stated temperature range as higher Power generation per square meter $\left(\mathrm{kW} / \mathrm{m}^{2}\right)$ and efficiency; and lower power production cost of per unit electricity $(\$ / W)$

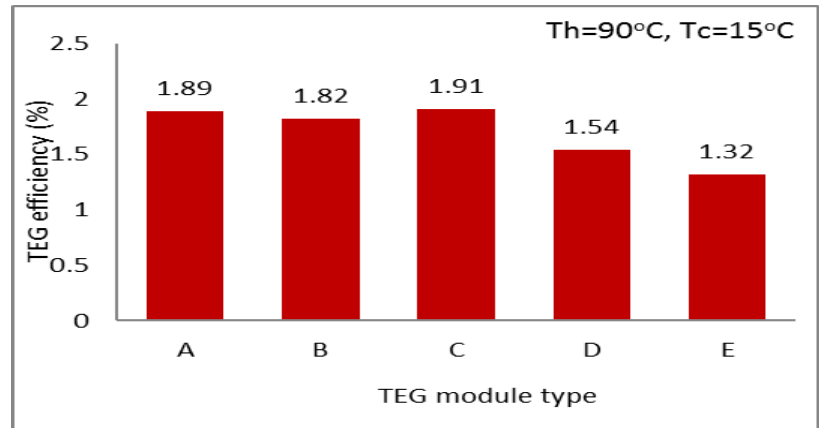

Fig. 4: Efficiency of selected TEG module under specified operating temperature

\section{Mathematical modelling}

A conceptual model has been shown in figure 5 for power generation from low grade waste heat using TEG. The model contains hot water channel and cold-water channel with counter flow arrangement; thermoelectric module is sandwiched between two channels. Thermal paste has been used between water channel and thermoelectric module to avoid the air gap and to accelerate heat transfer rate. The system is surrounded by thermal insulation to reduce the heat loss.

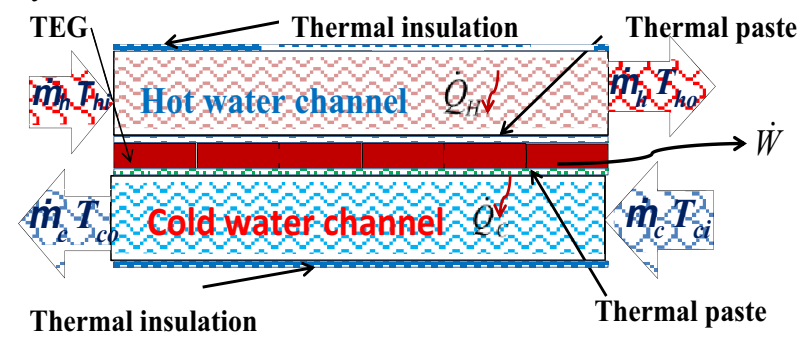

Fig.5: Conceptual design for power generation

Energy balance equation for hot and cold fluids are shown in equation (1) and (2) respectively.

$$
\begin{gathered}
\dot{Q}_{H}=\dot{m}_{h} c_{p h}\left(T_{h i}-T_{h o}\right) \\
\dot{Q}_{C}=\dot{m}_{c} c_{p c}\left(T_{c o}-T_{c i}\right)
\end{gathered}
$$

The energy balance equation can be written in following form

$$
\begin{aligned}
& \dot{Q}_{H}(d, \dot{m}, w)=U(d, \dot{m}, w) A(d, w)\left(T_{h i}-T_{c o}\right) \\
& \dot{Q}_{C}(d, \dot{m}, w)=U(d, \dot{m}, w) A(d, w)\left(T_{h o}-T_{c i}\right)
\end{aligned}
$$

$U$ is the overall heat transfer coefficient and $A$ is Surface area. Here heat transfer rate has represented as function of all variables such as channel thickness (d), flow rate (m) and length/width (w). More explanation can be found in next section on this paper.

Consider amount of power generation by TEG is negligible compared to total of heat transfer in hot or cold-water channel. By equating equation 3 and 4

$$
T_{h i}-T_{c o}=T_{h o}-T_{c i}
$$

On the other hand, from equation (1) and (4)

$$
\dot{m}_{h} c_{p h}\left(T_{h i}-T_{h o}\right)=U(d, \dot{m}, w) A(d, w)\left(T_{h o}-T_{c i}\right)
$$

Outlet temperature of hot water channel can be calculated from equation 6 and denoted by equation 7 as function of variables.

$$
T_{h o}(d, \dot{m}, w)=\frac{\dot{m}_{h} c_{p h} T_{h i}+U(d, \dot{m}, w) A(d, w) T_{c i}}{\dot{m}_{h} c_{p h}+U(d, \dot{m}, w) A(d, w)}
$$

Consider hot side flow rate and cold side flow rate is equal $\left(\dot{\mathrm{m}}_{\mathrm{h}}=\dot{\mathrm{m}}_{\mathrm{c}}=\dot{\mathrm{m}}\right)$ and specific heat is also equal $\left(c_{p h}=c_{p c}=c_{p}\right)$. Equation (7) can be written as

$$
T_{h o}(d, \dot{m}, w)=\frac{\dot{m} c_{p} T_{h i}+U(d, \dot{m}, w) A(d, w) T_{c i}}{\dot{m} c_{p}+U(d, \dot{m}, w) A(d, w)}
$$

So, outlet temperature of cold channel can be found from equation (5)

$$
T_{c o}(d, \dot{m}, w)=T_{h i}-T_{h o}(d, \dot{m}, w)+T_{c i}
$$

Total heat transfer rate through TEG can be found from equations 1 and 8 . For simplicity, hot water and coldwater flow rate have considered equal. So, total heat transfer rate in both channels would be identical if heat to electricity conversion has considered as negligible. Total heat transfer rate can be estimated from following equation 10.

$$
\dot{Q}_{H}=\dot{Q}_{C}=Q(d, \dot{m}, w)=\dot{m} c_{p} \frac{U(d, \dot{m}, w) A(d, w)\left(T_{h i}-T_{c i}\right)}{\dot{m} c_{p}+U(d, \dot{m}, w) A(d, w)}
$$

Q amount heat transfer through TEG and a portion of this heat converted to electricity by TEG which depends on the efficiency of thermoelectric module. Power Generated by Thermoelectric generator (TEG) is

$$
P_{T E G}(d, \dot{m}, w)=Q(d, \dot{m}, w) \eta_{T E G}
$$

$\eta_{T E G}=$ Heat to electrical power conversion efficiency of TEG.

\subsection{Calculation of overall heat transfer coefficient $(U)$}

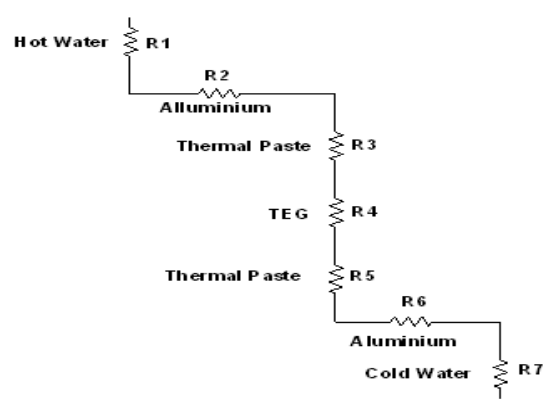

Fig.6: Thermal resistance for one unit

According to figure 5, the thermal resistance for one unit has been plotted in figure 5. Now, total thermal resistance is algebraic sum of all resistances which can be found from following equation 12 . So, overall heat transfer coefficient can be defined by equation 13 . 


$$
\begin{gathered}
R_{t}(d, \dot{m}, w)=R_{1}(d, \dot{m}, w)+R_{2}+R_{3}+R_{4}+R_{5}+ \\
R_{6}+R_{7}(d, \dot{m}, w) \\
U(d, \dot{m}, w)=\frac{1}{R_{t}(d, \dot{m}, w)}
\end{gathered}
$$

Convection resistance of hot water and cold water can be calculated by using following equation;

Equation to calculate Reynolds's number

$$
\operatorname{Re}(d, \dot{m}, w)=\frac{\rho v(d, \dot{m}, w) D(d, w)}{\mu}
$$

Reynolds's number is identical for both hot water and cold-water channel as flow rate and dimensions considered as same.

Friction factor;

$$
\begin{gathered}
F(d, \dot{m}, w)=(0.790 * \log (\operatorname{Re}(d, \dot{m}, w))-1.64)^{\wedge}(-2) \\
\text { If } 3000<\operatorname{Re}<5 \times 10^{\wedge} 5 \\
F(d, \dot{m}, w)=64 / \operatorname{Re}(d, \dot{m}, w)
\end{gathered}
$$$$
\text { If } \operatorname{Re}<3000
$$

Nusselt number can be found by below equations

$$
\begin{gathered}
N u(d, \dot{m}, w)=\frac{\frac{F(d, \dot{m}, w)}{8}(\operatorname{Re}(d, \dot{m}, w)-1000) * P_{r}}{1+12.7 *(F(d, \dot{m}, w) / 8)^{0.5}\left(P_{r}^{2 / 3}-1\right)} \\
N u=3.66^{\text {If } 3000<\operatorname{Re}<5 \times 10^{\wedge} 5}
\end{gathered}
$$

If $\operatorname{Re}<3000$

So, heat transfer coefficient for hot water and cold water can be calculated by using below equation

$$
h(d, \dot{m}, w)=\frac{N_{u}(d, \dot{m}, w) K_{w}}{D}
$$

Now convection resistance of hot water and cold water is

$$
R_{1}(d, \dot{m}, w)=R_{7}(d, \dot{m}, w)=\frac{1}{h(d, \dot{m}, w)}
$$

Conductive resistance of aluminium in both hot and cold side can be calculated by following equation

Where, $a_{t}=$ thickness of aluminium and $K_{m}=$ thermal conductivity of aluminium.

$$
R_{2}=R_{6}=\frac{a_{t}}{K_{m}}
$$

\subsection{Parasitic Power calculation}

In this study, pump will be required to maintain the flow rate in hot and cold-water channel. A significant amount of power is losses due to friction which depends on rate of water flow and the dimensions of channel. Since flow rate and dimensions of both channel considered as same, the parasitic power losses also will be identical; which can be estimated by following equation

$$
p_{h}(d, \dot{m}, w)=p_{c}(d, \dot{m}, w)=\frac{\dot{m}}{\rho} \Delta \mathrm{P}(d, \dot{m}, w) * \eta_{p}
$$

Where $\Delta \mathrm{P}=$ pressure difference and $\eta_{\mathrm{p}}=$ Pump efficiency Total parasitic power is sum of required power for hot and cold-water pumping power

$$
P_{L}(d, \dot{m}, w)=p_{h}(d, \dot{m}, w)+p_{c}(d, \dot{m}, w)
$$

\subsection{Effective net power}

Effective net power can be calculated by subtracted parasitic power from total gross power. Net power can be optimized by maximize gross power and reduced parasitic power; both are depends on flow rate and dimensions of channel. So, proper heat exchanger/channel design and selection of appropriate flow rate is imperative to optimize ne power.

$$
P_{N e t}(d, \dot{m}, w)=P_{T E G}(d, \dot{m}, w)-P_{L}(d, \dot{m}, w)
$$

\section{Model validation by experiments}

An experimental setup has been prepared to validate the mathematical model. The dimensions of used hot and cold-water channel were identical with length $=1 \mathrm{~m}$, width $=0.08 \mathrm{~m}$ and gap height $=9 \mathrm{~mm}$ which shown in figure 7 .

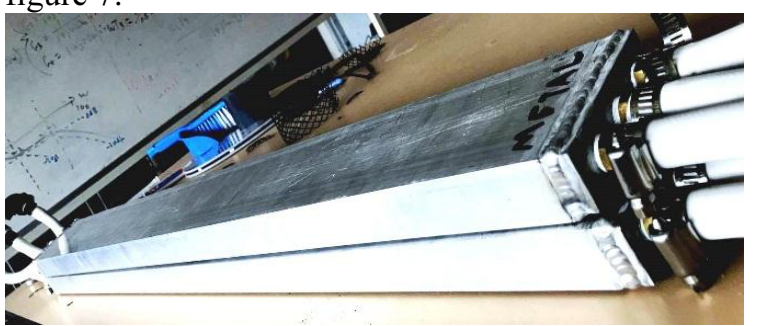

Fig. 7: Size of lab scale hot and cold-water channel

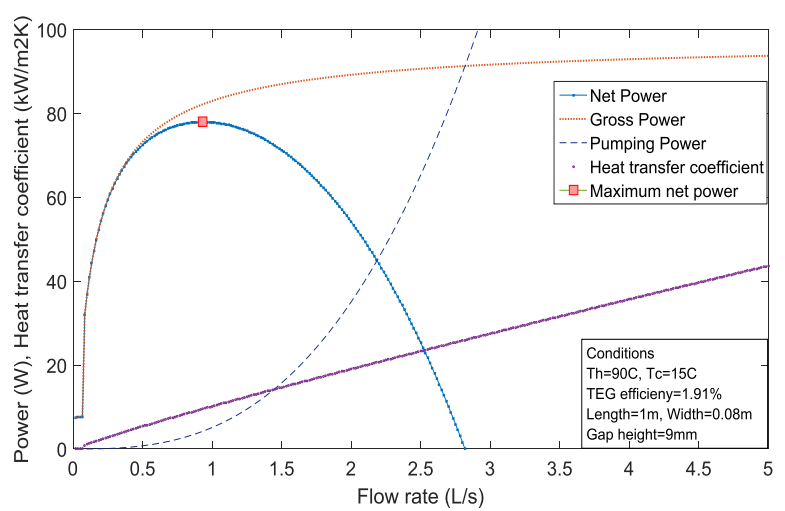

Fig. 8: Power and heat transfer coefficient

Figure 8 shows the estimated performance of TEG based power generation system using the proposed mathematical model. Gross power from TEG upsurges with the increment of flow rate as heat transfer coefficient increases. Net power also increases with the rise of flow rate up to $0.94 \mathrm{~L} / \mathrm{s}$. Interestingly, if we increase the beyond this point, gross power rises but net power started to diminish which turn into zero for the flow rate $2.8 \mathrm{~L} / \mathrm{s}$. This happen due to pumping power tremendously increase beyond the flow rate $0.94 \mathrm{~L} / \mathrm{s}$, pumping power is equal to gross power for flow rate 2.8 $\mathrm{L} / \mathrm{s}$ which turn into zero gross power. If flow rate increased beyond this point, pumping power is higher than gross power and net power goes negative. 


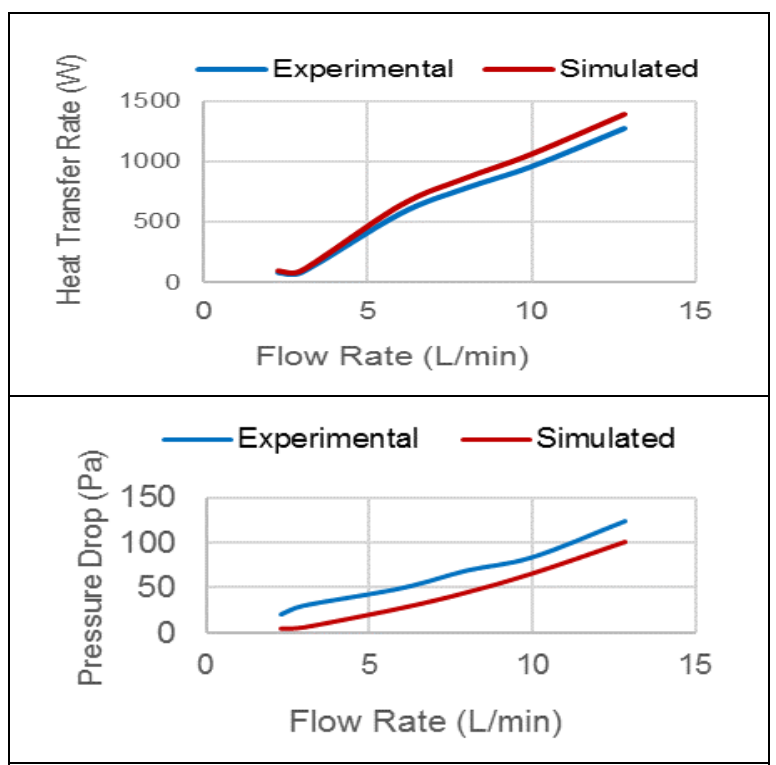

Fig. 9: Comparison between experimental and simulated results

We have run few initial experiments using the channel shown in figure 7. Though thermoelectric modules were not installed yet, we were able to run some experiments to find heat transfer rate from hot stream to cold stream and pressure drop in both channel. Experimental and simulation results are compared in figure 9. The water flow was varied between $1 \mathrm{~L} / \mathrm{min}$ to $13 \mathrm{~L} / \mathrm{min}$ with hot inlet temperature of $52.5^{\circ} \mathrm{C}$ and cold inlet was $21.5^{\circ} \mathrm{C}$. The obtained heat transfer rate from experiments was $5-10 \%$ less than simulated results, which happened due to poor thermal insulation. In the case of pressure drop in channel, experimental value was $20 \%$ higher compared to simulated results due to friction losses for hose connection. The surface inside the channel is not fully smooth which increase the friction loss hence increased the friction loss.

\section{Conclusion}

In this work, five TEG modules have been selected from wide range of commercially available thermoelectric generator. An experiment has been undertaken to select the most suitable thermoelectric module for focused operating conditions. A theoretical model has been proposed to estimate the generated power from thermoelectric based power generation system. This model can calculate the gross power from TEG, parasitic power and net power for all possible combinations and able to predict the optimum net power for specified temperature range and conditions. The optimum operating conditions such as flow rate, heat exchanger dimensions can be found from the proposed model. An experiment has been undertaken to verify the simulated results. Simulated and experimental results are closely matched which can give confident about proposed mathematical model for further use.

\section{References}

1. Ebrahimi, K., G.F. Jones, and A.S. Fleischer, A review of data center cooling technology, operating conditions and the corresponding low-grade waste heat recovery opportunities. Renewable and Sustainable Energy Reviews, 2014. 31: p. 622-638.

2. Orr, B., et al., A review of car waste heat recovery systems utilising thermoelectric generators and heat pipes. Applied Thermal Engineering, 2016. 101: p. 490-495.

3. Remeli, M.F., et al., Experimental investigation of combined heat recovery and power generation using a heat pipe assisted thermoelectric generator system. Energy Conversion and Management, 2016. 111: p. 147157.

4. Matsuda, K., Low heat power generation system. Applied Thermal Engineering, 2014. 70(2): p. 1056-1061.

5. Rana, S., et al., Modelling and Optimization of Lowtemperature Waste Heat Thermoelectric Generator System. Energy Procedia, 2017. 110: p. 196-201.

6. Rowe, M.D., et al. Thermoelectric recovery of waste heat-case studies. in Energy Conversion Engineering Conference, 1997. IECEC-97., Proceedings of the 32nd Intersociety. 1997. IEEE.

7. Crane, D.T. and G.S. Jackson, Optimization of cross flow heat exchangers for thermoelectric waste heat recovery. Energy Conversion and Management, 2004. 45(9): p. 1565-1582.

8. Niu, X., J. Yu, and S. Wang, Experimental study on lowtemperature waste heat thermoelectric generator. Journal of Power Sources, 2009. 188(2): p. 621-626.

9. Gou, X., H. Xiao, and S. Yang, Modeling, experimental study and optimization on low-temperature waste heat thermoelectric generator system. Applied energy, 2010. 87(10): p. 3131-3136.

10. Kim, S., et al., A thermoelectric generator using engine coolant for light-duty internal combustion enginepowered vehicles. Journal of electronic materials, 2011. 40(5): p. 812.

11. Gou, X., et al., A dynamic model for thermoelectric generator applied in waste heat recovery. Energy, 2013. 52: p. 201-209.

12. Orr, B.G. and A. Akbarzadeh, Experimental testing of a car exhaust heat recovery system utilising TEGs and heat pipes. SAE-A Vehicle Technology Engineer-Journal, 2016. 2(1). 